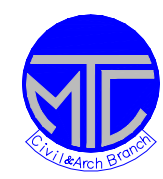

\title{
ICCAE
}

Military Technical College

Kobry Elkobbah,

Cairo, Egypt 6hㅡ International Conference On Civil \& Architecture Engineering

\section{EXPERIMENTAL TESTING AND NUMERICAL MODELLING OF RC RECTANGULAR COLUMNS UPGRADED USING FRP WRAPPING}

\author{
M.A. Bitar ${ }^{1}$, H.M. Farag ${ }^{2}$, M.E. Issa ${ }^{3}$ \& M.A.N. Abdel-Mooty ${ }^{4}$
}

\begin{abstract}
In order to evaluate the behaviour of square and rectangular concrete columns wrapped by fibre reinforced polymer (FRP) sheets, subjected to axial loading were studied. Six specimens were tested and numerically analyzed using finite element method (FEM). The factors affecting the performance of FRP wrapping in rectangular columns under the action of axial loads are considered in this paper. These factors include the rectangularity ratio of the column cross section. Techniques to improve the performance of strengthening rectangular columns were also proposed and evaluated in the paper. Such techniques include rounding the sharp edges of the columns, and transferring square into circular columns using mortar. A total of six half-scale reinforced concrete columns, divided into two groups, are tested in this research. The first group consists of three square columns, while the second group consists of three rectangular columns. A three-dimensional finite element models are developed to examine the structural behaviour of the RC columns before and after applying FRP sheet. Nonlinear finite element analysis is performed using the ANSYS program. Special elements SOLID 65, LINK 8, and SOLID 64 were used to represent concrete, discrete reinforcing steel bars, and FRP sheet, respectively. The experimentally evaluated nonlinear material properties for each material component are defined for the nonlinear finite element analysis. The numerically obtained results are correlated to the experimental ones. The developed finite element analysis models are capable of effectively simulating the behaviour of square and rectangular columns confined by FRP sheets when the proper material properties are adopted.
\end{abstract}

Keywords: Nonlinear finite element analysis; column strengthening; CFRP; experimental testing.

\footnotetext{
${ }^{1}$ Graduate student, Syria.

${ }^{2}$ Egyptian Armed Forses.

${ }^{3}$ Professor, Department of Structural Engineering, Cairo University, Egypt.

${ }^{4}$ Professor, Department of Construction Engineering, American University in Cairo, Egypt.
} 


\section{Introduction}

The use of FRP wrapping for repair and strengthening existing RC columns has gained increasing attention in recent years [1-3]. FRP wrapping was proposed for increasing the ductility of column under axial and axial-flexural loading through confinement [4-8], improving insufficient shear strength [9]. Due to uniform confinement, FRP wrapping has been proven effective for strengthening circular columns [4]. Other studies showed the improvement in seismic capacity of square columns wrapped with FRP jacket [7,8]. It was recommended that the sharp corners of the column must be rounded to avoid premature failure of the FRP jacket due to stress concentration at the corners. Studies conducted on wrapping rectangular columns showed inferior performance to that of circular and square columns [5 and 10]. Finite element analysis (FEA) can effectively simulate the behaviour of square columns confined by FRP sheets when the proper numerical model is adopted [11]. Kachlakev et al [12] developed a three-dimensional finite element model to examine the structural behavior of the Horsetail Creek Bridge in Oregon both before and after applying FRP laminates. The comparisons between ANSYS predictions and field data are made in terms of concrete strains. The analysis shows that the FE bridge model does not crack under the applied service truckloads.

The work presented in this paper describes the first phase of a two-phase research program addressing the performance of $\mathrm{RC}$ rectangular columns strengthened using FRP wrapping jacket. The first phase is an experimental study to evaluate the effectiveness of using FRP wrapping for repair and seismic upgrading of square and rectangular RC columns in buildings. The second phase is a theoretical investigation to develop a numerical model capable to accurately predict the actual behaviour of the repair techniques. The factors affecting the performance of FRP wrapping in rectangular columns under the action of axial load including the rectangularity ratio of the column cross section are considered in this paper. Techniques to improve the performance of strengthening rectangular columns are also proposed and evaluated in the paper. Such techniques include rounding the sharp edges of the columns and transferring square into circular columns using mortar. A total of six half-scale reinforced concrete columns, divided into two groups, are tested in this research. The two groups of columns consist of three square columns, and three rectangular columns which were tested under axial loadings. 


\section{Experimental program and setup}

The test program in this research aims at studying the various parameters affecting the behaviour of reinforced concrete rectangular columns strengthened using FRP wrapping under axial load. To study the effect of column cross section rectangularity ratio, a total of six half-scale reinforced concrete columns, divided into two groups, are tested under increasing axial loads to failure in this research. The first group of columns, Group I, consists of three square columns; CS1, CS2 and CS3. The second group, Group II, consists of three rectangular columns; CR1, CR2 and CR3. The details of the test specimens and program are summarized in Table 1.

The average concrete strength for the test specimens after 28 days from casting is $32.5 \mathrm{MPa}$. Mild steel bars of diameter $6 \mathrm{~mm}$ were used for stirrups while high grade steel bars of diameter $12 \mathrm{~mm}$ were used for longitudinal reinforcement. Carbon FRP sheet were used for jacket wrapping of the column specimens. The physical and mechanical properties of the used CFRP are displayed in Table 2. The installation of the FRP jacket necessitates surface treatment. Sandpaper and sand blasting were used for concrete surface preparation before applying the epoxy resin used for installing the FRP wrapping.

The sharp corners of the rectangular columns were rounded to avoid premature failure of the jacket due to stress concentration at sharp corners. Epoxy was applied uniformly on the entire face of the concrete column as well as on the FRP laminate. The fabrics were then compressed to the concrete surface with a roller. The thickness of the epoxy layer was controlled to be about $1.2 \mathrm{~mm}$. The specimens were treated at room temperature for at least 24 hours before testing. 
Table 1: Summary of test program and setup

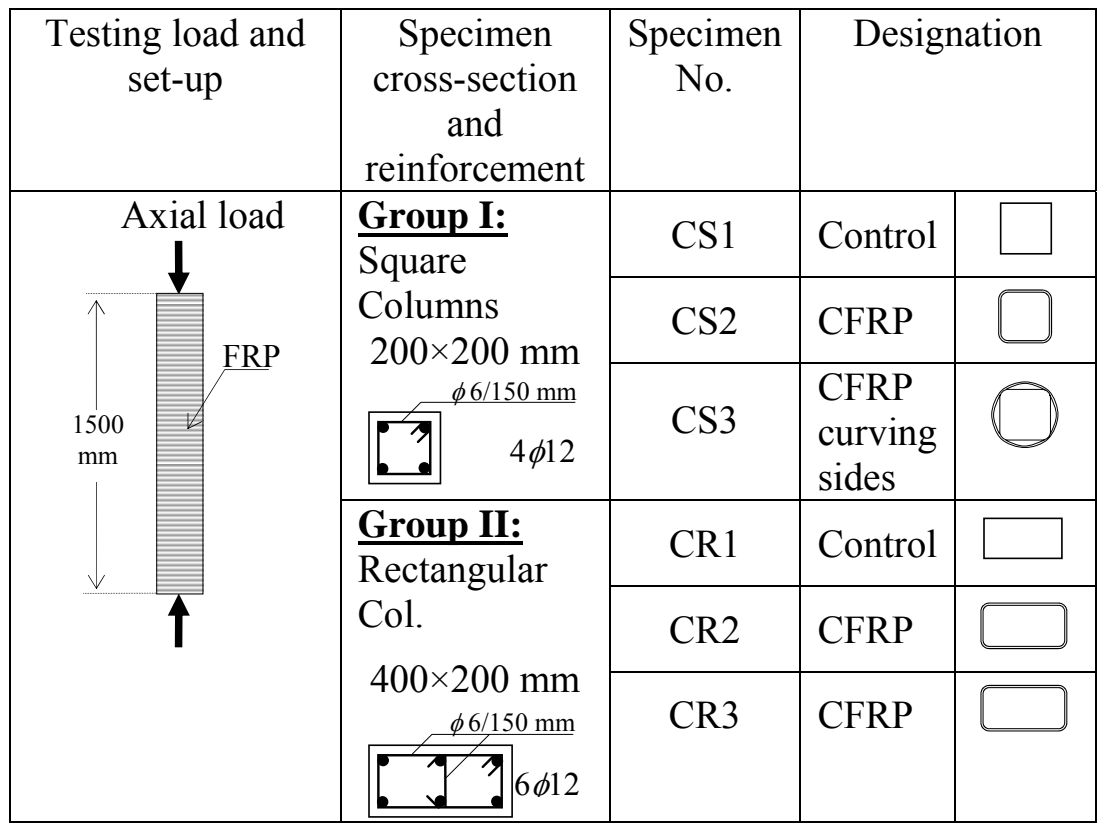

Table 2: Physical and mechanical properties of CFRP

\begin{tabular}{|l|c|}
\hline Property & CFRP \\
\hline Tensile strength in fibre direction (MPa) & 965 \\
\hline Elongation at breaking (\%) & 1.33 \\
\hline Tensile modulus (GPa) & 73 \\
\hline Nominal laminate thickness (mm) & 0.13 \\
\hline Fabric width (mm) & 305 \\
\hline
\end{tabular}

Specimens were instrumented with 2 LVDT's at the mid-height to measure out of plane deformation. Strain gauges were attached to longitudinal reinforcements and the stirrups at the column mid-height to measure longitudinal and transverse strain during loading. Surface strain gauges were also mounted to the concrete surface and to the CFRP jacket. Those measurements are used for verification of the detailed numerical models developed in this research. The measured load, displacements, and strains at the various locations were fed into the data acquisition system and recorded for further processing and analysis. Figure 1 shows schematic diagrams of the test set-up. Figure 2 shows sample specimens during testing and at failure. 


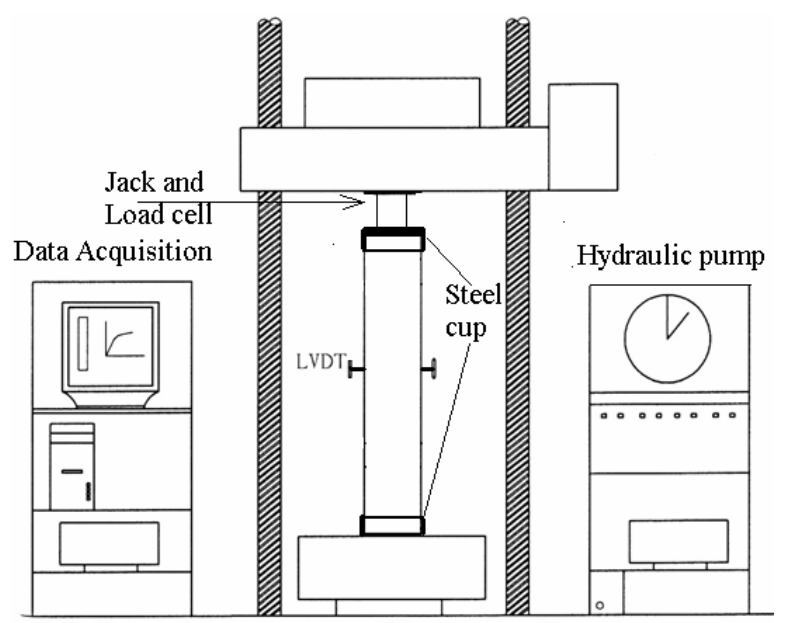

Figure 1: Schematic diagram for test set-up

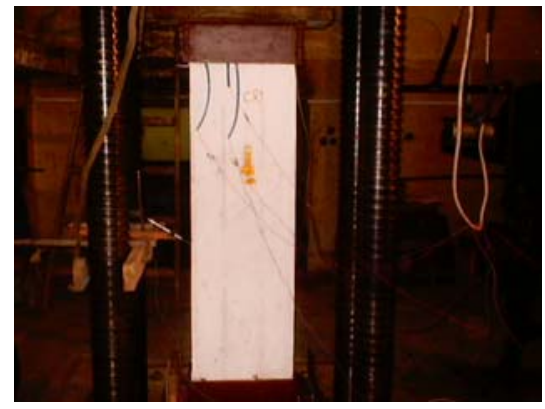

a) Control Specimen CR1 during testing

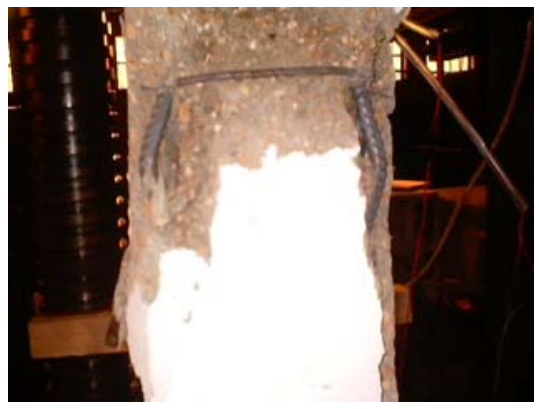

b) Failure of CR1

Figure 2: Axial load testing and failure of control specimen CR1

\section{Experimental results}

The specimens were tested under increasing axial loads until failure. The square column control specimen formed inclined cracks at an average stress of $30.2 \mathrm{~N} / \mathrm{mm}^{2}$ followed by fast progressive failure in the form of falling off the concrete cover and buckling of longitudinal reinforcement. As for specimens CS2, and CS3, the confinement provided by the CFRP jacket delayed the failure to higher stresses values of $48.2 \mathrm{~N} / \mathrm{mm}^{2}$ for CS2 and $48.9 \mathrm{~N} / \mathrm{mm}^{2}$ for CS3. At failure the CFRP jacket was ruptured due to hoop tensile stresses after which buckling of steel longitudinal bars occurred. The rectangular specimens showed similar behaviour up to failure except that the effect of confinement due to the CFRP jacket was less pronounced. Figures 3-6 show the variation of axial strain and lateral strain with axial stress for square and rectangular column specimens respectively. Figure 7 compares the average axial stress at failure for axially loaded specimens. FRP confinement increases the ultimate capacity of axially loaded square columns by approximately 50\%. The confinement effect was less pronounced for rectangular columns where the increase in the ultimate capacity was about $21 \%$. Transferring square column to circular one slightly increase the average failure stress by $1.5 \%$, however the overall load capacity of the column is increased by $5.2 \%$ from $193 \mathrm{kN}$ to $203 \mathrm{kN}$ due to increasing the cross section. 


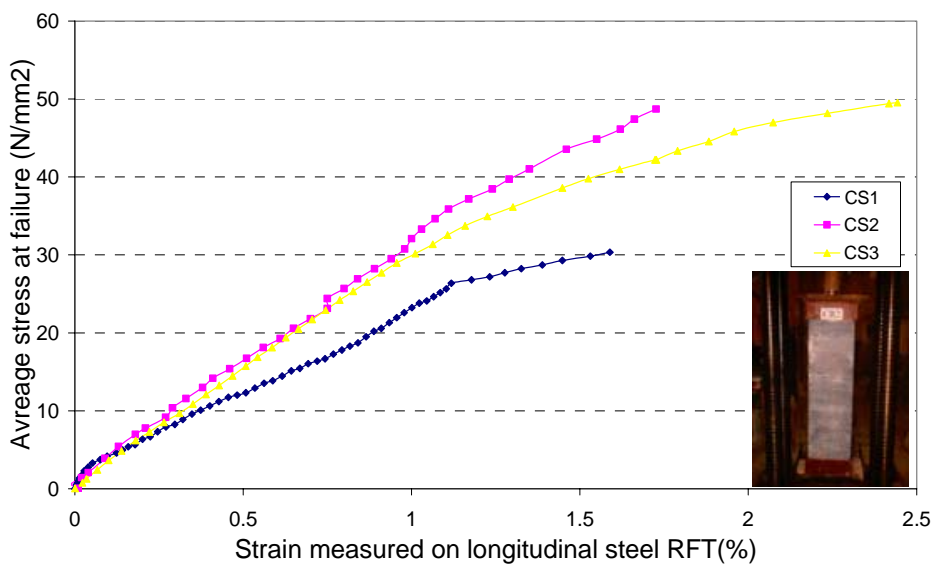

Figure 3: Variation of axial strain with axial stress for square columns

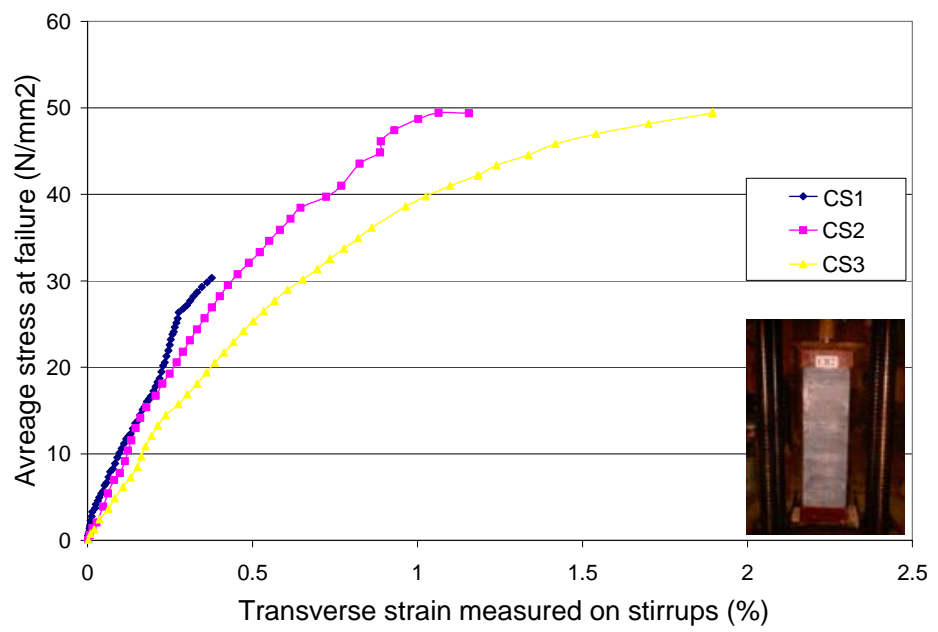

Figure 4: Variation of transverse strain with axial stress for square columns.

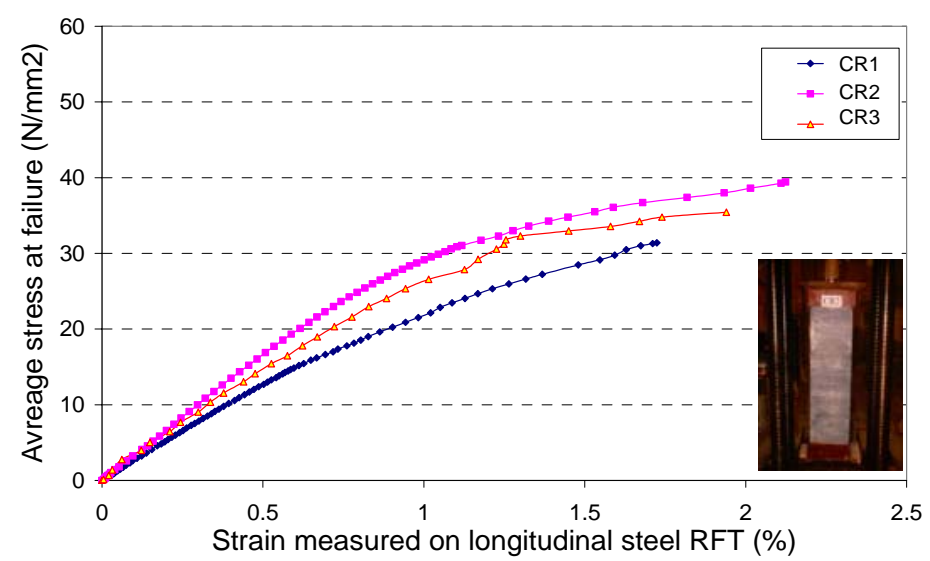

Figure 5: Variation of axial strain with axial stress for rectangular columns 


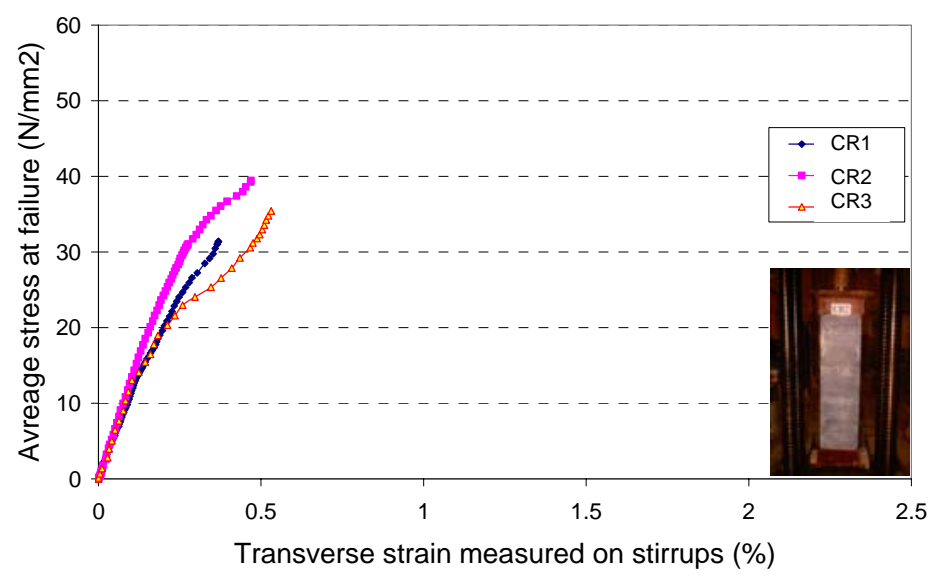

Figure 6: Variation of transverse strain with axial stress for rectangular columns.

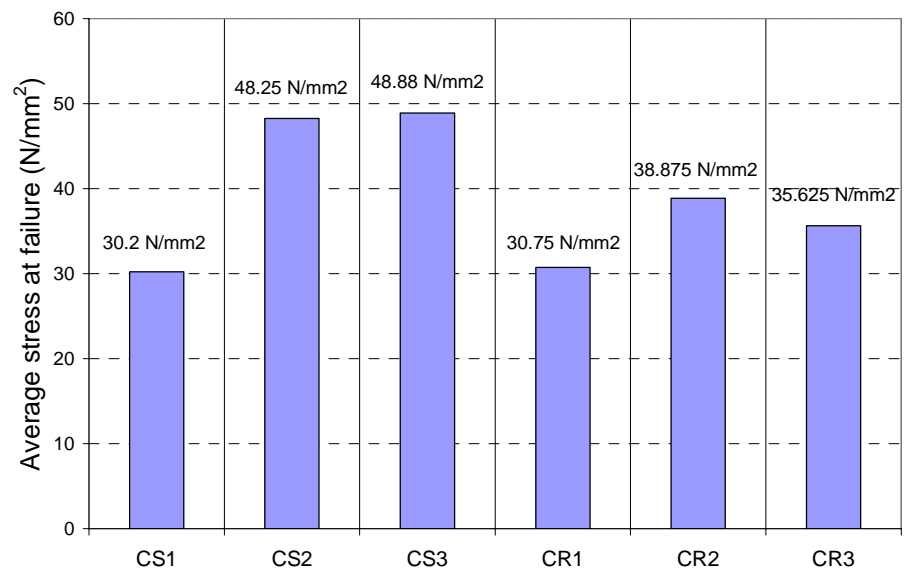

Figure 7: Average axial stress at failure for axially loaded columns.

\section{Finite Element Modeling for Nonlinear Analysis using ANSYS program}

Nonlinear finite element analysis is performed using the ANSYS program [13]. Special element SOLID65 is used to represent concrete in the models. The element is defined by eight nodes having three translational degrees of freedom at each node in the $\mathrm{x}, \mathrm{y}$, and $\mathrm{z}$ directions as shown in Figure 8. This element is capable of cracking in tension and crushing in compression. Cracking is treated as a "smeared band" of cracks, rather than discrete cracks in ANSYS and occurs as soon as stresses in the concrete exceed the tensile strength of the material [13]. For the modeling of crushing, the material is assumed to crush if all principal stresses are in compression, when the material at an integration point fails in uniaxial, biaxial, or triaxial compression. However, the crushing capability of the SOLID65 element is turned off in this study to avoid a "rapid collapse" in the FE simulation. This element can model concrete with or without reinforcing bars.

If the rebar capability is used, the bars will be smeared throughout the element. Nevertheless, in this study a discrete bar element is used instead of the smeared reinforcing approach. The most important aspect of the SOLID65 element is the treatment of nonlinear material 
properties. The response of concrete under loading is characterized by a distinctly nonlinear behavior. The typical behavior of concrete used in this study is expressed in the stress-strain relationship for concrete subjected to uniaxial loading as shown in Figure 8. Uniaxial tensile and compressive strengths $\left(\sigma_{\mathrm{cu}}\right.$ and $\left.\sigma_{\mathrm{t}}\right)$ and uniaxial nonlinear stress-strain relationship for concrete are defined as parts of the material properties in the SOLID65 element. The first two parameters are required to define failure surface for the concrete due to a multiaxial stress state.

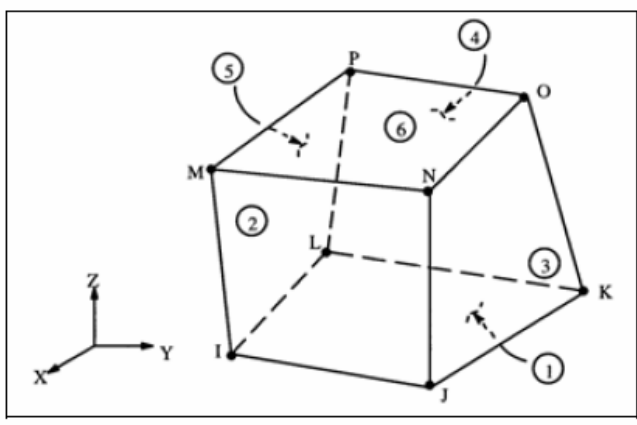

a) Nonlinear 3-D SOLID65 element

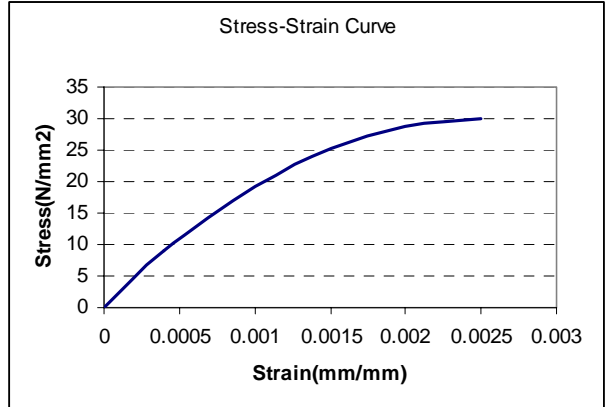

b) idealized stress-strain curve for concrete

Figure 8: Non-linear modeling for concrete elements.

The LINK8, 3-D spar element, is used to represent the reinforcing steel bar. It is a uniaxial tension-compression element that can also include nonlinear material properties. Two nodes having three translational degrees of freedom at each node define the element. The elasticperfectly plastic representation is assumed for the reinforcing steel bars in this study.

The FRP sheets are modeled by the solid 64, a three-dimensional element used for modeling anisotropic solid structures. The element is defined by eight nodes having three translational degrees of freedom at each node in the nodal $\mathrm{x}, \mathrm{y}$, and $\mathrm{z}$ directions. The element has stress stiffening and large deflection capabilities. Other options are available to suppress the extra displacement shapes and to define the printout locations. Nodes of the FRP solid elements were connected to those of adjacent concrete solid elements in order to satisfy the perfect bond assumption. Figure 9 illustrates the connectivity of the various element used in this study after [14]. The details of modeling for nonlinear analysis of the tested specimens are shown in Figure 10.

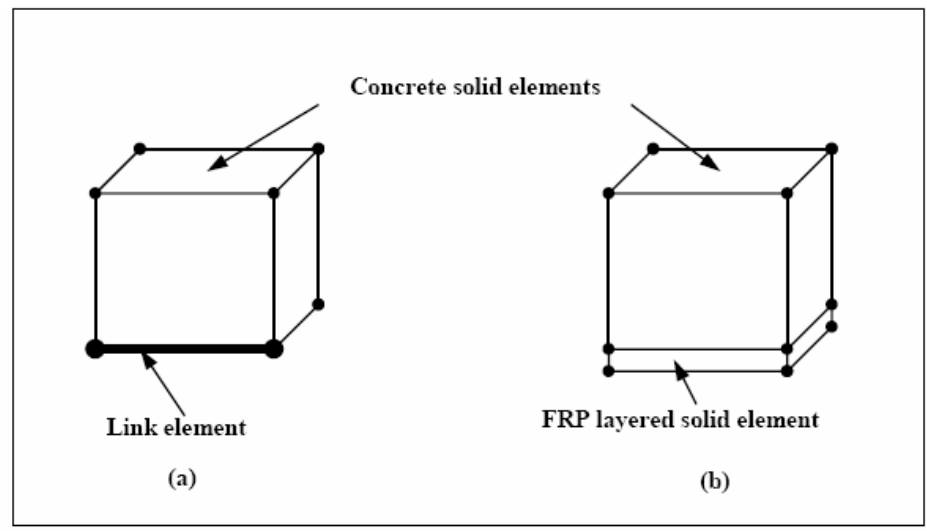

Figure 9: Element connectivity: (a) concrete solid and link elements; (b) concrete solid and FRP solid elements [14]. 
A summary of the material properties used for each component in the FE columns model is shown in Table 3.

Table 3: Material properties

\begin{tabular}{|l|c|c|c|}
\hline \multirow{2}{*}{ Type of Material } & \multicolumn{3}{|c|}{ Material Properties } \\
\cline { 2 - 4 } & Poisson ratio $v$ & E ( MPa) & Strength (MPa) \\
\hline Concrete & 0.2 & 21000 & $\begin{array}{c}\sigma_{\mathrm{cu}}=30 \\
\sigma_{\mathrm{t}}=2.8\end{array}$ \\
\hline Reinforcing steel $12.21 \mathrm{~mm}$ diameter & 0.3 & 196000 & 568.6 \\
\hline Reinforcing steel $6.04 \mathrm{~mm}$ diameter & 0.3 & 185000 & 320 \\
\hline FRP sheet $0.13 \mathrm{~mm}$ thick & 0.299 & 230000 & 965 \\
\hline
\end{tabular}

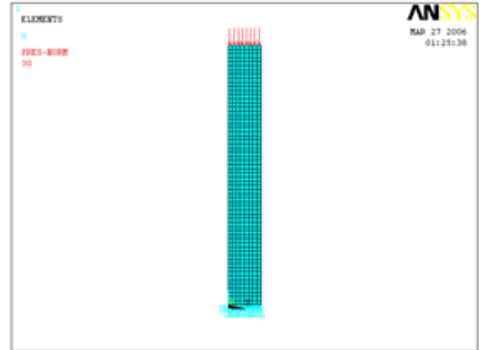

a) Meshing and Boundary Condition for CS1

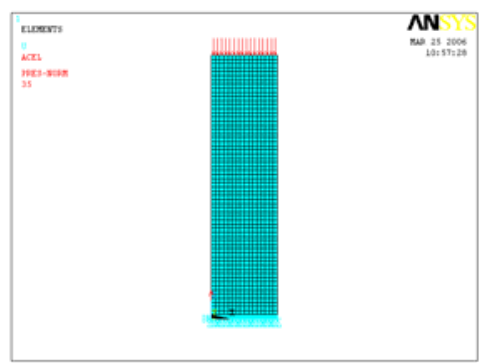

d) Meshing and Boundary Condition for CR1

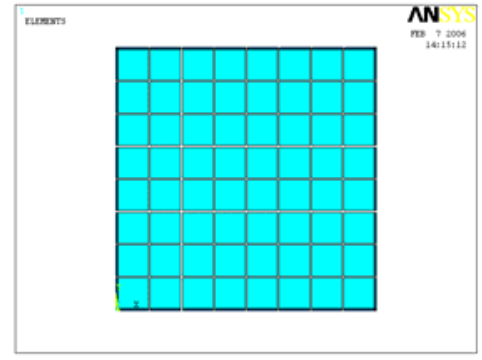

b) FE mesh for-CS2

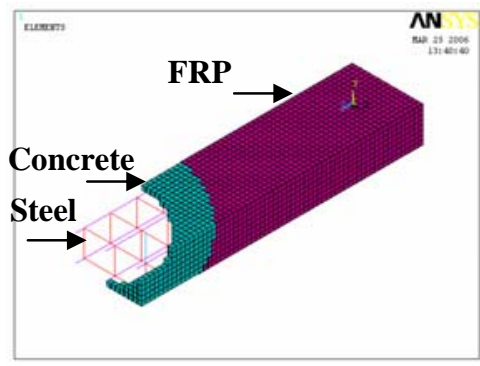

f) Details of CR3

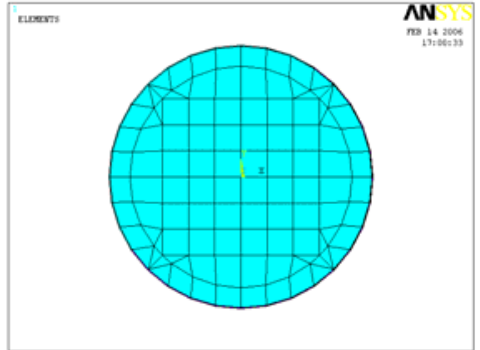

c) FE mesh for CS3

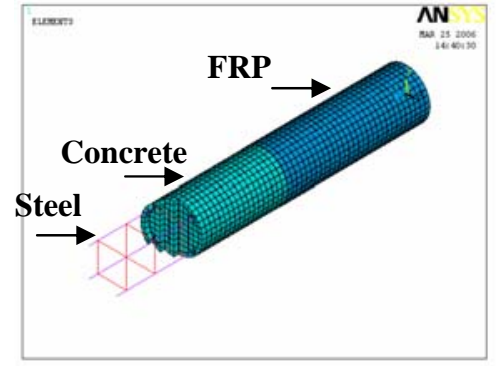

g) Details of CS3

Figure 10: Finite element mesh and details of the considered models.

\section{Analysis of results}

The nonlinear finite element analysis conducted using ANSYS software [13] yielded a state of stresses and cracking pattern similar to the observed ones during testing. Figure 11 shows the crack distribution in the numerical model at failure compared to that of the tested specimens. Figures 12 and 13 show the correlation between theoretical and experimental results, in terms of axial load-strain curves, for square and rectangular specimens, respectively. Table 4 compares the ultimate load at failure for the numerical and experimental models for the tested specimens. Table 5 compares the strain values for the experimental and theoretical models at different points in the tested specimens. 
Proceedings of the 6th ICCAE Conf. 16 -18 May, 2006

Table 4 Comparison of the ultimate load for theoretical modelling and experimental testing

\begin{tabular}{|l|c|c|c|c|c|c|}
\hline Specimen & CS1 & CS2 & CS3 & CR1 & CR2 & CR3 \\
\hline Experimental ultimate load kN & 1185 & 1930 & 2030 & 2481 & 3117 & 2800 \\
\hline Theoretical ultimate load kN & 1200 & 2020 & 2056 & 2670 & 3200 & 3000 \\
\hline \% Difference & 1.25 & 4.45 & 1.26 & 7 & 2.6 & 6.67 \\
\hline
\end{tabular}

Table 5 Experimental vs. theoretical strain values for the tested specimens.

\begin{tabular}{|l|c|c|c|c|c|c|}
\hline & \multicolumn{2}{|c|}{ Longitudinal Strain\% $\left(\varepsilon_{\mathrm{S}}\right)$} & \multicolumn{2}{c|}{ Transverse Strain\% $\left(\varepsilon_{\mathrm{S}}\right)$} & \multicolumn{2}{c|}{ Concrete or FRP Strain\% $\left(\varepsilon_{\mathrm{S}}\right)$} \\
\hline & Experimental & Theoretical & Experimental & Theoretical & Experimental & Theoretical \\
\hline CS1 & 1.758 & 1.52 & 0.343 & 0.486 & & \\
\hline CS2 & 1.755 & 1.641 & 1.275 & 1.13 & 0.856 & 0.734 \\
\hline CS3 & 2.44 & 1.14 & 1.894 & 1.78 & 0.724 & 0.67 \\
\hline CR1 & 1.72 & 1.6 & 0.37 & 0.35 & 1.6 & 1.62 \\
\hline CR2 & 2.124 & 2.04 & 0.469 & 0.446 & 1 & 1.05 \\
\hline CR3 & 1.94 & 1.85 & 0.531 & 0.512 & 0.886 & 0.8 \\
\hline
\end{tabular}

CRACKS AND CRUSHING

STEP $=1$ SUB $=8$

TIME $=1$

PRES-NORM 30

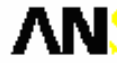

FEB 242006 $23: 23: 31$

Cracks in model CS1

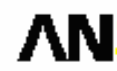

MAR 192006

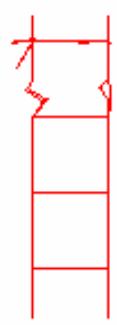

11:08:03

Buckling in model CS2

Buckling of reinforcement in specimen CS2

Figure 11: Comparison of cracks at failure between analytical and experimental models. 


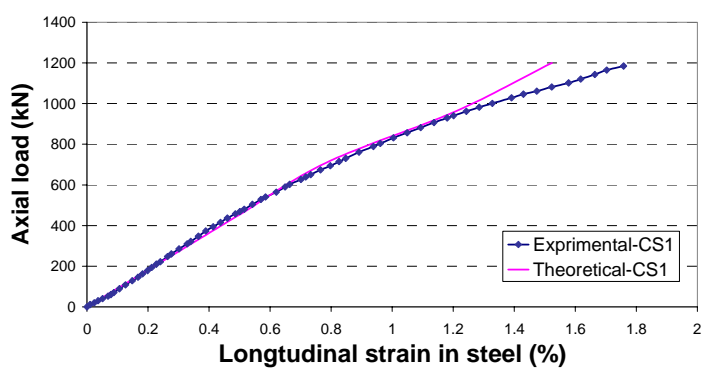

a) Axial load vs. long strain in CS1

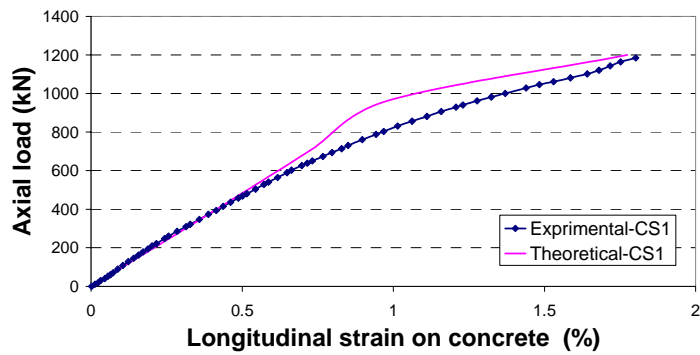

c) Axial load vs. concrete Strain in CS1

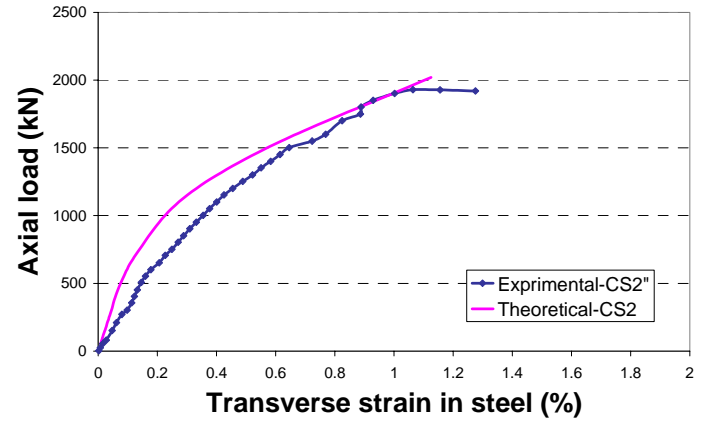

e) Axial load vs. transverse strain in CS2

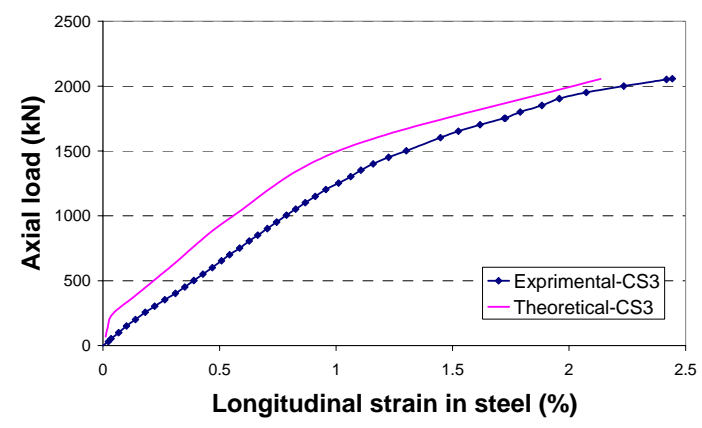

g) Axial load vs. longitudinal strain in CS3

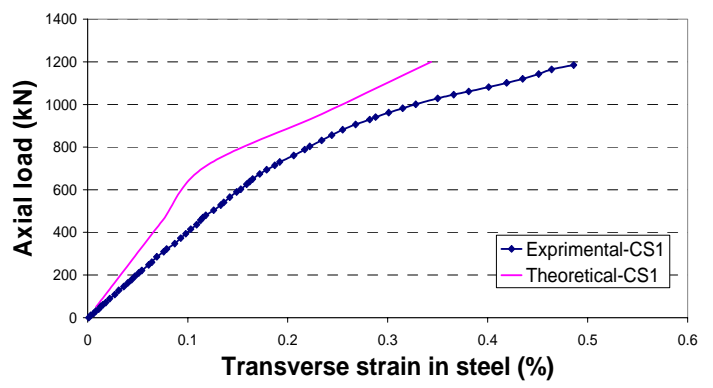

b) Axial load vs. transverse strain in CS1

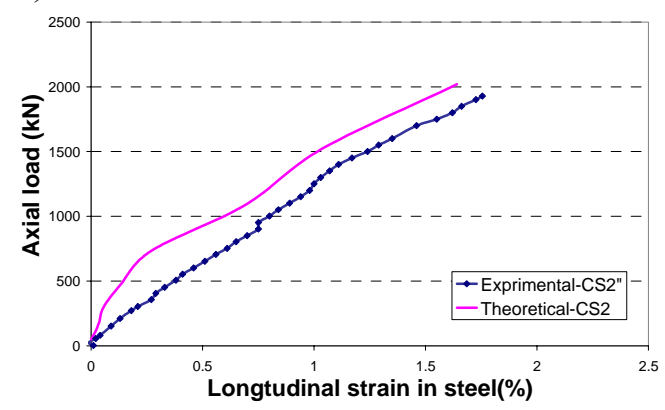

d) Axial load vs. longitudinal strain in CS2

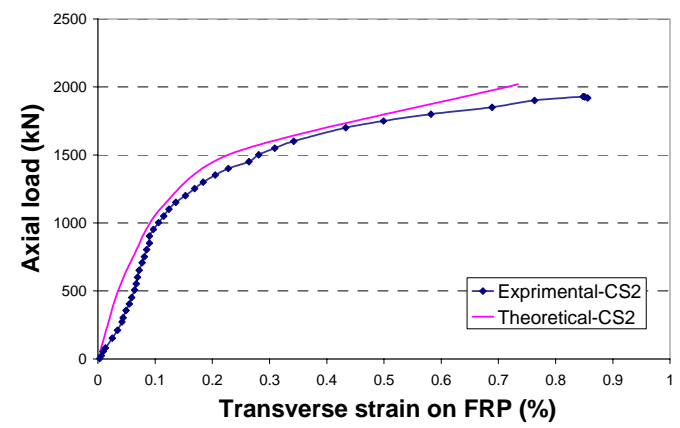

f) Axial load vs. FRP trans. strain in CS2

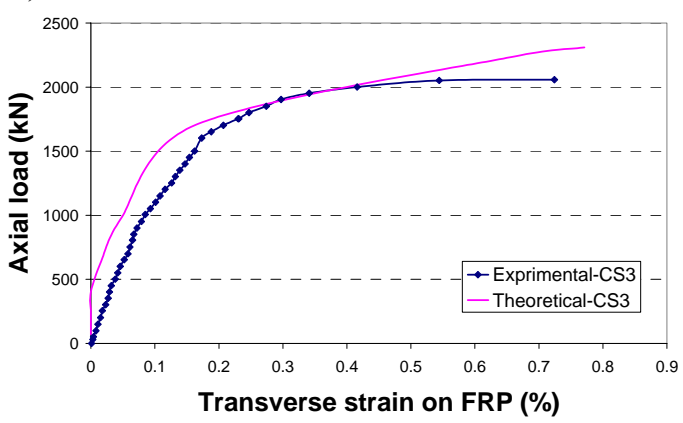

h) Axial load vs. FRP trans. strain in CS3

Figure 12: Correlation of theoretical and experimental results for square test specimens. 


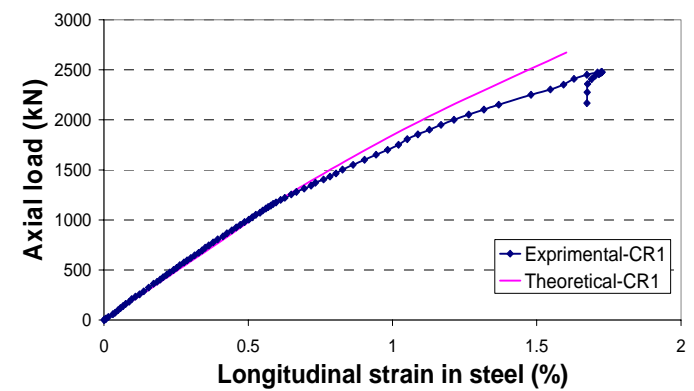

a) Axial load vs. long strain in CR1

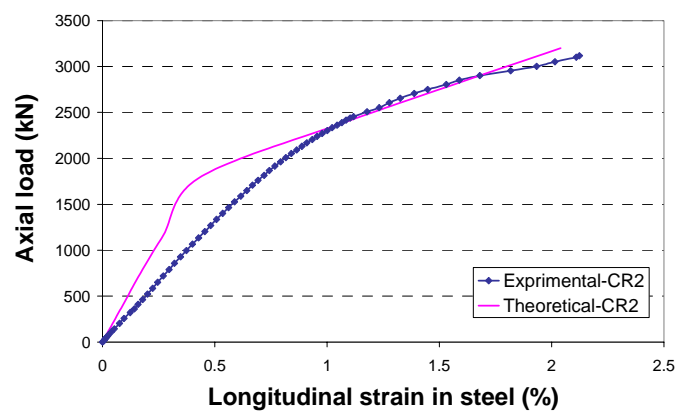

c) Axial load vs. long strain in CR2

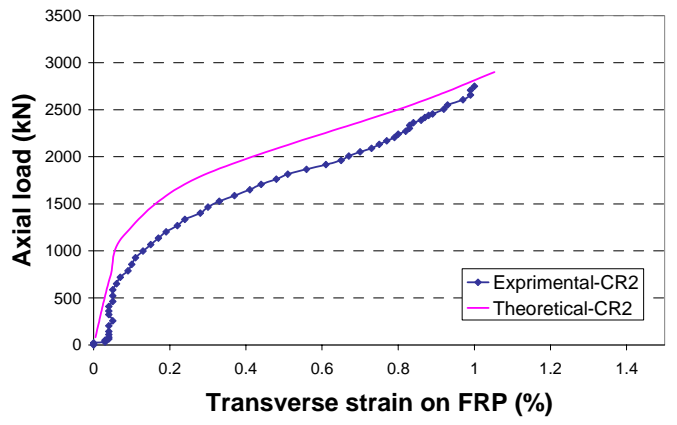

e) Axial load vs. FRP trans. strain in CR2

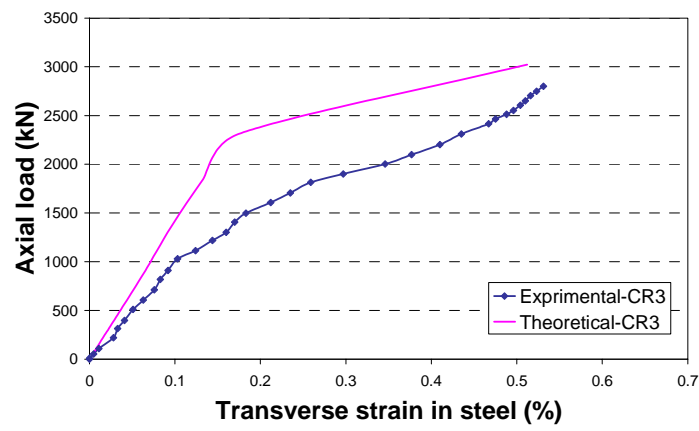

g) Axial load vs. transverse strain in CR3

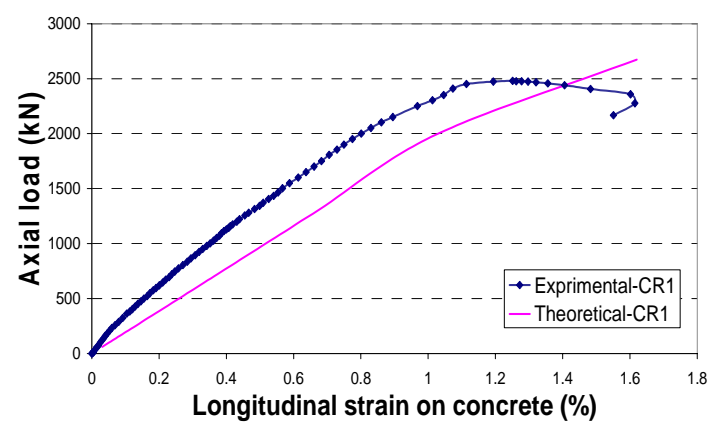

b) Axial load vs. concrete Strain in CR1

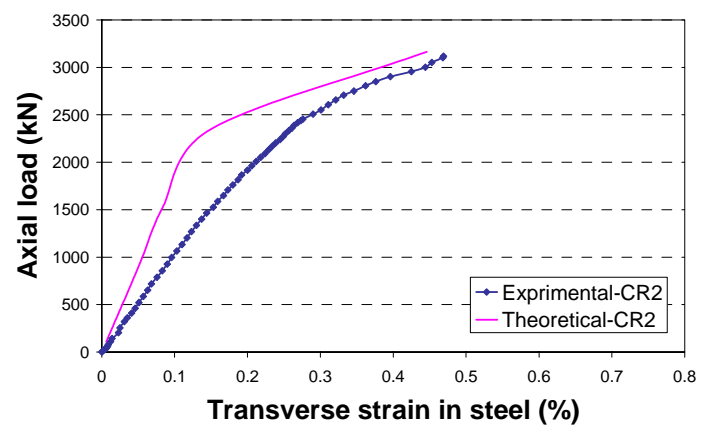

d) Axial load vs. transverse strain in CR2

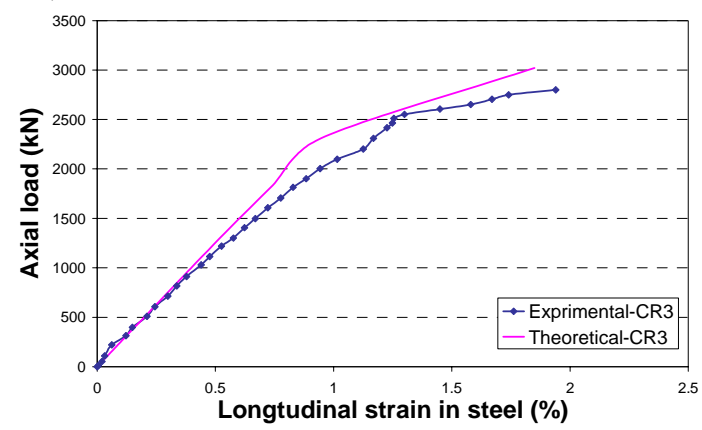

f) Axial load vs. long strain in CR3

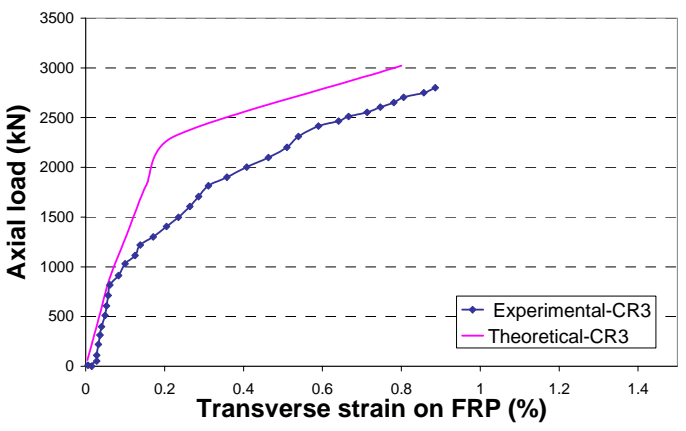

h) Axial load vs. FRP trans. strain in CR3

Figure 12: Correlation of theoretical and experimental results for rectangular test specimens. 


\section{Summary and conclusions}

The performance of six RC square and rectangular columns strengthened using FRP wrapping jacket under axial load was experimentally evaluated. The loads, displacements and strains during testing were recorded for further numerical study. It was found that strengthening RC columns using FRP wrapping is much more efficient in square columns than in rectangular columns. Failure stresses increased due to FRP wrapping by $50 \%$ in square columns and $21 \%$ in rectangular columns. Transferring square columns to circular columns to improve FRP confinement increases the ultimate stress by only $1.5 \%$.

Numerical finite element models were developed for the tested specimens and analyzed using ANSYS software. The developed numerical models were able to represent the nonlinear behavior the materials as well as cracking. The correlation between experimental and numerical results revealed the accuracy of the developed finite element models. Thus, the developed models can be used for further numerical parametric study for the effect of the various parameters on the performance of strengthened columns other than those considered in this study.

\section{References}

[1] Lehman, D.E., Gookin, S.E., Nacamuli, A.M. \& Moehle, J.P, Repair of earthquakedamaged bridge columns. ACI Structural journal, 98(2), pp. 233-242, 2001.

[2] Mosallam, A.S. (ed.). Innovative System for Seismic Repair and Rehabilitation of Structures - Design and Application, Proc. (SRRS2), Technomic Publishing co., Inc., 2000.

[3] Tan, K.H. (ed.). Fibre-Reinforced Polymer Reinforcement for Concrete Structures, Proc. of the Sixth International Symposium on FRP Reinforcement for Concrete Structures, Singapore, 8-10 July, 2003.

[4] Fam, A.Z. and Rizkalla, S.H., "Confinement model for axially loaded concrete confined by circular fiber-reinforced polymer tubes.” ACI Structural journal, 98(4), pp. 451-461, 2001.

[5] Wang, Y.C. \& Restrepo, J.I., Investigation of concentrically loaded reinforced concrete columns confined with glass fibre-reinforced polymer jackets. ACI Structural journal, 98(3), pp. 377-385, 2001.

[6] Chaallal, O. \& Shahawy, M., Performance of fiber-reinforced polymer-wrapped reinforcement concrete column under combined axial-flexural loading. ACI Structural journal, 97(4), pp. 659-668, 2000.

[7] Mahmoud, Kh., Fouad, E., Ramadan, M.O. and Abd-Elalim, A., Behaviour of axially loaded square RC column confined with sandwich FRP wraps. Proc. International Conference: Future Vision and Challenges for Urban Development, Paper SG96F, Cairo, 20-22 December 2004.

[8] Allam, H.M., Strengthening of square columns by a New Technique. Proc. International Conference: Future Vision and Challenges for Urban Development, paper SG167F, Cairo, 20-22 December 2004.

[9] Haroun, M. A. and Elsanadedy, H.M., Seismic retrofit of shear-deficient reinforced concrete bridge columns by advanced composite jackets. Proc. Structural Composite for Infrastructure Applications, Aswan, Egypt, 2002. 
[10]Hosny A., Shahin, H. Abdelrahman, A, \& El-Afandy, T., Uniaxial tests on rectangular columns strengthened with CFRP. Proc. Structural Composite for Infrastructure Applications, Aswan, Egypt, 17-20 Dec., 2002.

[11]P. Feng, X. Z. Lu and L. P. Ye, Experimental research and finite element analysis of square concrete columns confined by FRP sheets under uniaxial compression. Proc. $17^{\text {th }}$ Australasian Conference on the Mechanics of Structures and Materials, Gold Coast, Australia, pp. 71-76, 2002.

[12] Kachlakev, D.I. "Finite element analysis of historic bridge strengthened with FRP laminates." Paper 003, Third International Conference on Composites in Infrastructure, San Francisco, California, June 10-12, 2002.

[13] ANSYS User's Manual, Revision 7. (2000). ANSYS, Inc. is a UL registered ISO 9001:2000 Company. Canonsburg, Pennsylvania, 2000.

[14] Kachlakev, D. and Miller, T. "Finite Element Modeling of Reinforced Concrete Structures Strengthened with FRP Laminates" Final Report SPR316, Oregon Department of Transportation and Federal Highway Administration, May 2001. 